\title{
External strengthening of reinforced concrete beam with opening by bamboo fiber reinforced composites
}

\author{
Siew Choo Chin • Kong Fah Tee $\mathbb{B}$ - Foo Sheng Tong • Shu Ing Doh • \\ Jolius Gimbun
}

Received: 5 March 2020/ Accepted: 28 October 2020/Published online: 11 November 2020

(C) The Author(s) 2020

\begin{abstract}
This paper presents the structural behaviour of reinforced concrete (RC) beams with and without openings strengthened externally with bamboo fiber reinforced composite (BFRC) plates in shear and flexure, respectively. Mechanical properties include tensile and flexural strength of epoxy, polyester and vinyl-ester based BFRC plates with $0 \%, 10 \%, 20 \%, 30 \%$ and $40 \%$ fiber volume fractions were evaluated. A total of fourteen beams were cast to evaluate the structural behaviour of RC beams strengthened with BFRC plates. All the beams were tested to failure under four-point bending. The results presented were in terms of load-deflection behaviour,
\end{abstract}

Electronic supplementary material The online version of this article (https://doi.org/10.1617/s11527-020-01572-y) contains supplementary material, which is available to authorised users.

S. C. Chin · F. S. Tong · S. I. Doh

Department of Civil Engineering, College of Engineering, Universiti Malaysia Pahang, Lebuhraya Tun Razak, 26300 Gambang, Kuantan, Pahang, Malaysia

S. C. Chin · K. F. Tee $(\bowtie)$

Faculty of Engineering \& Science, University of

Greenwich, Central Avenue,

Chatham Maritime ME4 4TB, Kent, UK

e-mail: K.F.Tee@gre.ac.uk

J. Gimbun

Center of Advanced Research in Fluid Flow, Universiti

Malaysia Pahang, Lebuhraya Tun Razak,

26300 Gambang, Kuantan, Pahang, Malaysia failure mode and crack pattern. A comparison was also made between the performance of epoxy, polyester and vinyl-ester based BFRC plates in shear strengthening of RC beams with openings. Results revealed that the presence of openings in the shear zone reduced the original beam capacity of the control beam to about 52-55\%. Shear strengthening of RC beams with openings using epoxy based BFRC plates showed significant improvement in regaining the beam structural capacity to approximately $32-36 \%$ higher than the un-strengthened beams. Meanwhile, strengthening of RC beams in flexure with epoxy based BFRC plates managed to regain the beam original capacity up to $98 \%$ of the control beam. Bamboo fiber composite reinforced with epoxy, polyester and vinyl-ester resins of $40 \%$ fiber volume fraction managed to regain the beam original capacity up to $82 \%$. It was found that BFRC plates could divert and mitigate the formation of cracks away from the strengthened region as well as improved the beam ductility.

Keywords Bamboo fiber reinforced composite $($ BFRC) $\cdot$ Beam · Experimental · Flexural · Reinforced $\cdot$ Strengthening $\cdot$ Shear

\section{Introduction}

Natural fiber has advantages as a sustainable, environmentally friendly and low-cost construction 
material. In the past, most of the investigations on natural fiber composites such as kenaf [29], bamboo [18, 24, 35], jute [16], sisal Ramesh et al. [26] focused on their physical, mechanical and thermal properties, effects of fiber extraction methods as well as types of fiber treatment. Due to the high tensile strength and tensile modulus of natural fibers, further investigations were conducted to study the potential of natural fiber reinforced composites for structural strengthening. Various investigations were conducted on kenaf, jute, jute rope fiber as polymer composites for both flexural and shear strengthening [5]. Hafizah et al. [17] studied the flexural behaviour of RC beams externally strengthened by kenaf fiber reinforced polymer composites with $50 \%$ fiber volume content. The findings revealed that all strengthened beams managed to improve the flexural strength by $40 \%$. Alam et al. [3] investigated the shear strengthening of RC beams with kenaf fiber polymer composites. The composite strengthened beam had $33 \%$ ultimate failure load as compared to un-strengthened control beam. On the other hand, there were investigations of using jute rope composite plate [4] and jute fiber textile Sen and Reddy [32] for flexural strengthening of RC beams. The strengthened beam with jute rope composite plate was 58\% higher compared to the control beam [4]. Meanwhile, natural sisal reinforced composite systems were also studied on the flexural strengthening of RC beams Sen and Reddy [31]; Bharath and Reddy [8]; [20].

Bamboo is ideal for use as strengthening material due to its excellent mechanical strength, readily available and economical to harvest. There are about 1200 species of bamboo worldwide with the total area of about 22 million $\mathrm{hm}^{2}$. They grow rapidly within 6 to 8 months in tropical and subtropical regions, and some species even can grow in temperate and subarctic regions. Most of the past studies investigated the physical and mechanical properties of the bamboo fibers [10, 11, 21, 24, 27], Zhang et al. [38 and bamboo fiber reinforced composites (BFRC) [19, 19 36, 37]. However, no previous study on external structural strengthening by BFRC, and hence this is the main objective of this work.

An opening in RC beams is needed to accommodate for the service ducts and piping. However, the presence of opening reduces the cross-sectional area of the beam, which leads to the reduction of the original beam capacity Chin et al. [12], [22]. This can cause severe cracks around the opening and may increase the beam deflection. Strengthening of RC beams with openings are usually required when openings need to be created due to changes in the purpose of the building. To avoid hacking and drilling the existing structures for the inclusion of steel reinforcement, external strengthening using fiber reinforced polymer (FRP) materials is usually the best alternative to avoid further damage to the beam. Many investigations were conducted on the flexural and shear strengthening of RC beams with and without openings using FRP [1, 2, 6, 7, 13, 15, 25, 30, 33, 34]. Most of the reported literatures utilized natural fiber composites for flexural strengthening of RC beams, but very limited studies were conducted on shear strengthening. Furthermore, the previous work focused on the solid RC beam, there were no studies on natural fiber reinforced composites to strengthen $\mathrm{RC}$ beams with openings in shear zone.

In this study, the potential use of bamboo fiber reinforced composites and epoxy adhesives in strengthening of solid RC beams in flexure and RC beams with openings in shear was experimentally investigated. The failure modes and the enhancement of the load-carrying capacity of RC beams strengthened with BFRC plates were discussed.

\section{Materials and method}

\subsection{Preparation of fibers to fabricate composite plates}

A total of twelve unidirectional epoxy-based BFRC plates specimens were fabricated using hand lay-up method of treated bamboo fibers. The fiber content in the composite for beam strengthening was $40 \%$ fiber volume fraction. BFRCs based on epoxy, polyester and vinyl ester with fiber loading ranging from 0 to $40 \%$ were tested for comparison. Epoxy-based composite was chosen because it has the highest ultimate tensile and flexural strength. The fibers were cleaned, dried and straightened before placing into the stainless-steel mould. Imperfection of fibers such as dark spot and weak in strength were removed. As the bamboo culms in this study mainly had nodes between the lengths of $450 \mathrm{~mm}$; hence, the fibers were then cut into equal lengths of $450 \mathrm{~mm}$. 


\subsection{Removal of lignin from bamboo}

Matured bamboo (Gigantochlea scotechini) aged between three to four years were obtained from Raub, Pahang, Malaysia. The bamboo node was removed and cut into splints with size approximately $1500 \times 20 \times 10 \mathrm{~mm}$. The bamboo splint was treated with $10 \% \mathrm{wt} / \mathrm{v}$ sodium hydroxide solution for $48 \mathrm{~h}$ at room temperature, following the method in our earlier work [14]. Subsequently the bamboo splints were removed from the sodium hydroxide solution and washed with distilled water. The bamboo fiber was obtained by mechanical defibrillation using a mill roller machine. The residual alkaline and broken lignin content from the fiber is washed before ovendried at $60{ }^{\circ} \mathrm{C}$ for $24 \mathrm{~h}$.

\subsection{Preparation of BFRC}

The BFRC plates for beam strengthening were fabricated by hand-lay-up method using a steel mould $120 \times 8 \times 450 \mathrm{~mm}$ consisted of base plate and top plate (see supplementary data Figure A1). The steel mould was cleaned, and a thin layer of honey wax was applied for easier removal of the composite plate after fabrication. The fibers were placed in the casting mould layer by layer. Equal amount of fibers was used for each layer. Three different polymer resins were used in this work which were epoxy, polyester and vinyl ester. The first layer of the bamboo fibers was arranged methodically on the adhesive and pressed gently using a spatula to ensure the fibers were soaked entirely in the resin. The second layer of resin poured on the first layer of bamboo fibers for interfacial bonding. Subsequently, another layer of bamboo fibers was manually aligned on top of the new resin layer. These steps were repeated until the mould is filled completely. Finally, pressure was applied on top of the mould to remove entrapped air. The BFRC specimens were cured at room temperature for $24 \mathrm{~h}$ to enable cross-linking between the fibers and thermosetting resin. Afterward, the specimens were post-cured at a temperature of $110{ }^{\circ} \mathrm{C}$ for $4 \mathrm{~h}$ in an oven. A similar method was used to prepare the BFRC specimen for tensile and flexural test. However, the size of steel mould of $250 \times 25 \times 5 \mathrm{~mm}$ and $127 \times 12.7 \times 6 \mathrm{~mm}$ was used instead to confirm with the requirement of ASTM D3039-17 and ASTM D790-17, respectively. The method to prepare the BFRC in this work is similar to that of Chin et al. [14]. The BFRC samples for tensile and flexural test are shown in Fig. 1.

\subsection{Tensile test}

A $50 \mathrm{kN}$ Shimadzu Universal Testing Machine (UTM) was used to measure the tensile strength of the BFRC specimen. All the specimen was prepared according to the ASTM D3039-17, i.e. dimension of $250 \times 25 \times 5 \mathrm{~mm}$. The measurement was performed at at a strain rate of $2 \mathrm{~mm} / \mathrm{min}$.

\subsection{Flexural test}

A $50 \mathrm{kN}$ Universal Testing Machine (UTM) was used to determine the flexural strength of BFRC with a dimension of $127 \times 12.7 \times 6 \mathrm{~mm}$. The BFRC specimen has a span to depth ratio of 16:1. The measurement was performed at a crosshead speed of $2 \mathrm{~mm} /$ min according to ASTM D790-17.

\subsection{Beam specimens}

The experimental program contained two beam groups. All the two groups, A and B were utilized to evaluate the effect of shear and flexural strengthening, respectively. The beams in group A consisted of controlled specimens (CB), where no strengthening was carried out, unstrengthened beams with openings

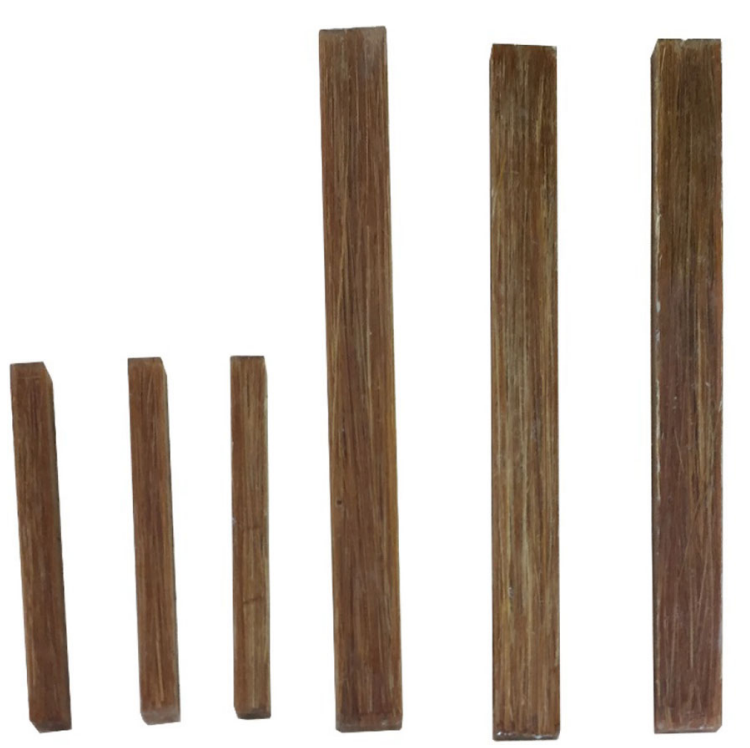

Fig. 1 The BFRC samples for tensile and flexural test 
in the shear spans (BUO) as well as beams with openings in the shear spans strengthened with BFRC based epoxy (EBSO), polyester (PBSO) and vinylester (VBSO) around the openings. The beams in group B were designed to investigate the effect of BFRC strengthening in the flexure zone, which consisted of controlled specimens, unstrengthened beams in flexure (BUF) and strengthened beams in the flexure zone (EBSF). The beams were prepared according to designation provided in Table 1 with two beams replicate prepared for each test. The dimensions of the beams were $120 \mathrm{~mm}$ in width, $300 \mathrm{~mm}$ in height and $1500 \mathrm{~mm}$ in length.

\subsection{Fabrication of beam specimens}

All RC beams were reinforced with two deformed steel bars with $10 \mathrm{~mm}$ diameter at the tension and compression sides of the beam in the longitudinal direction, $6 \mathrm{~mm}$ diameter steel stirrups at a spacing of $100 \mathrm{~mm}$ throughout the solid beam. To investigate the strengthening behaviour of RC beams with openings, two circular openings with diameter of $120 \mathrm{~mm}$ were created before casting at each shear span of the beam. In order to promote shear failure in beams in Group A, stirrups were not provided around the openings created at each of the shear spans to evaluate the effects of shear strengthening around the openings. On the other hand, beams in Group B were designed to be deficient in flexure by removing the stirrups in the flexural region. This is to evaluate the effect of flexural strengthening using BFRC plates. The reinforcement detailing of solid RC beam, RC beams with openings at the shear zones as well as RC beams without shear links in the flexure zone are shown in the supplementary data (Figures A2 to A4). A ready-mixed concrete obtained from Pamix Sdn Bhd with a specified compressive strength of $30 \mathrm{MPa}$ at the age of 28 days was used to cast the beams.

\subsection{Strengthening procedure}

The bonding surface of the RC beams was roughened using a scaling hammer to facilitate a better adhesion. Meanwhile, the bonding surface of BFRC plate was roughened by using a steel brush drill. The loose particles on the concrete surface and BFRC plates was cleaned with pressurised air and wiping cloth. The well-mixed Sikadur 30 adhesive was applied to the prepared substrate of RC beams and BFRC plates. The BFRC plate was then placed on top of the adhesive coating on the RC beams. The BFRC plates were then fixed on the surface of the beams by pressing from the center towards both ends using a plastic laminating roller to ensure the composite was well impregnated with the adhesive mix. The BFRC strengthened beam specimens were allowed for air curing at room temperatures for 7 days. It was to ensure the maximum strength and bonding were developed before testing.

\subsection{Strengthening configuration}

Two different surface strengthening schemes were adopted for shear and flexural strengthening of RC beams. In terms of shear strengthening of RC beam with openings, the BFRC plates were bonded at both top and bottom chords of the openings on one side of the beam surface in each shear spans. The BFRC plates were oriented in alignment of $45^{\circ}$ to the circular opening as shown schematically in Fig. 2a. The strengthening scheme at the openings was applied at one surface of the concrete beam. For the beams with deficient in the tension zone, two BFRC plates with a horizontal alignment of $0^{\circ}$ were attached next to next
Table 1 Description of testing specimens

\begin{tabular}{llll}
\hline Group & Beam designation & Opening location & Type of strengthening \\
\hline A & CB & Nil & No strengthening \\
& BUO & Middle of shear span & \\
EBSO & & Shear strengthening \\
& PBSO & & \\
VBSO & Nil & No strengthening \\
B & BUF & & \\
& EBSF & & Flexural strengthening \\
\hline
\end{tabular}




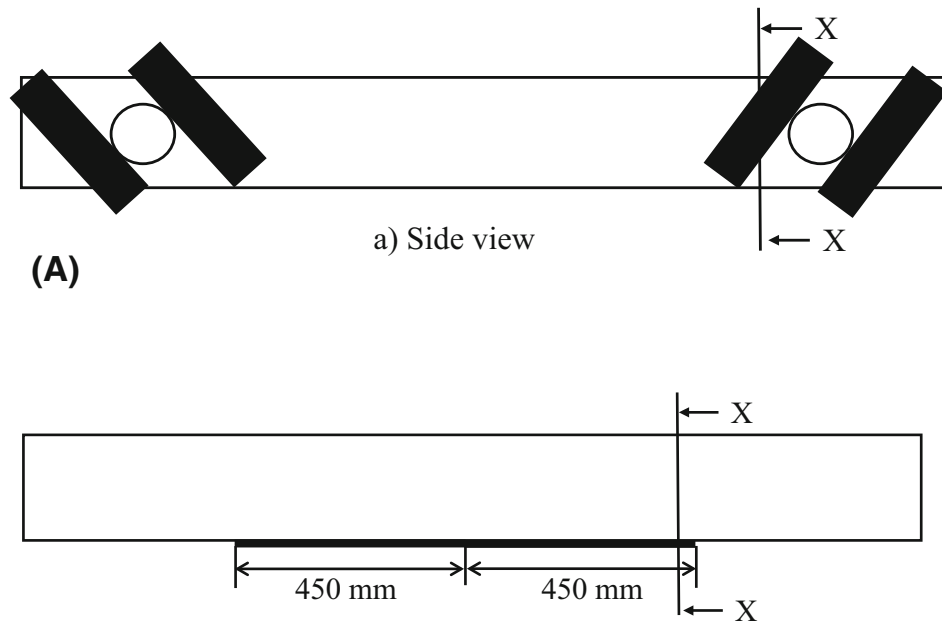

a) Side view

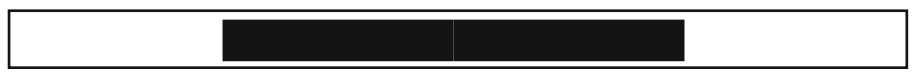

(B)

b) Underside view

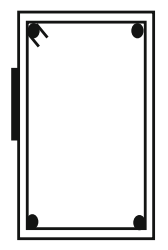

Section X-X

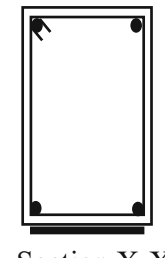

Section X-X

Fig. 2 Strengthening configuration of RC beams. a with openings in shear, $\mathbf{b}$ deficient in flexure

at the bottom soffit of the middle span of the beam as shown in Fig. $2 \mathrm{~b}$.

\subsection{Experimental setup}

A four-point loading configuration using a roller and pin was used to provide simply-supported boundary condition. The effective span of the beams was $1.3 \mathrm{~m}$. The beams were loaded by using hydraulic jack of 500 $\mathrm{kN}$ with a loading rate at $0.6 \mathrm{~mm} / \mathrm{min}$. A linear variable displacement transducer (LVDT) was used and placed in the middle span of the beams to measure the deflection. All samples were tested until the subjected load started to reduce and maximum displacement at the middle span had been reached. The failure mode of the beam was observed visually and the cracks were marked and recorded at every load increment up to beam failure.

\section{Results and discussion}

\subsection{Tensile and flexural properties of bamboo fiber reinforced composites}

Earlier, Chin et al. [14] shows that tensile and flexural strength of bamboo fiber reinforced composites made of epoxy (BFREC), polyester (BFRPC), and vinylester (BFRVC) enhanced the strength of the neat polymer by over $300 \%$. Tensile strength of epoxy is greater than those of polyester and vinyl-ester BFRCs as shown in Fig. 3. Flexural strength at $10 \%$ for all three BFRC type are significantly different $(p>0.05)$, but at higher fiber content (bamboo fiber $>30 \%$ ) the BFRC strength are not significantly different $(p<0.05)$. At higher bamboo fiber content, the mechanical properties of BFRC are independent to the type of polymer used. Since epoxy based BFRC with $40 \%$ fiber content shows the highest tensile and flexural strength, thus it was used for the concrete beam strengthening test in this work. It was observed that the ratio of tensile and flexural strength of the composite is not consistent at a different fiber content. This is due to several factors such as the mechanical properties of the resin used and the failure pattern of the bamboo fiber composite. According to Chin et al. [14], the failure mode of each composite is not exactly similar, which implies that the strength of the composite may differ appreciably. Hence, the flexural strength of the composite is not necessarily increasing at exactly similar rate with respect to the fiber content used. It is also known that the properties of vinyl ester, epoxy and polyester in terms of flexural and tensile strength as well as the elongation at break is different. 

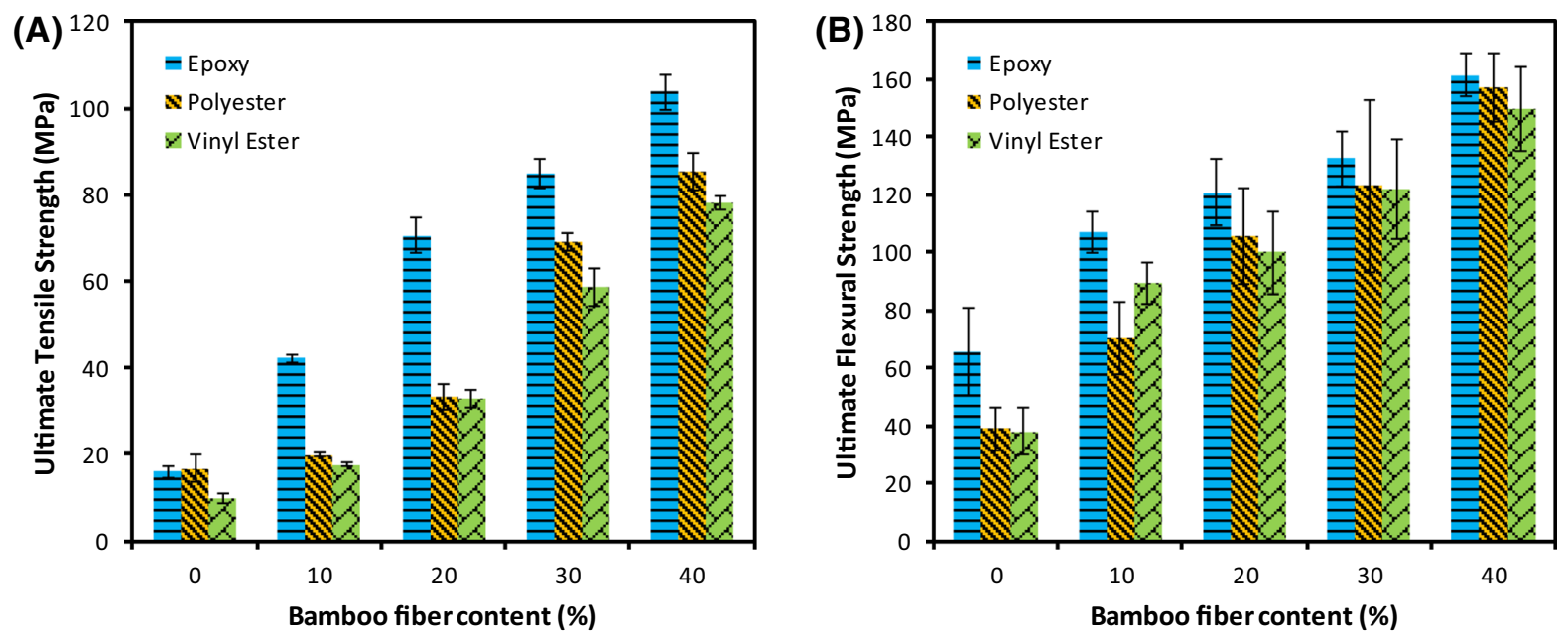

Fig. 3 The effect of bamboo fiber content to ultimate strength of BFRC A Tensile strength. B Flexural strength

Thus, the tensile to flexural strength ratio of bamboo composite with a different fiber content is not necessarily consistent. Earlier study on a composite made using a similar resin (epoxy, polyester and vinyl ester) by Rassmann et al. [28] also reported that the tensile to flexural strength ratio is not similar for the composite at a different fiber content.

\subsection{Structural behaviour of shear strengthened RC beams with openings using BFRC plates}

\subsubsection{Load-deflection behaviour}

Table 2 summarizes the experimental results of shear strengthened RC beams with openings using BFRC plates. The load-deflection behaviour of the control beams (CB), unstrengthened beams (BUO) as well as strengthened beams with openings with BFREC plates (EBSO) in shear are shown in Fig. 4. The control

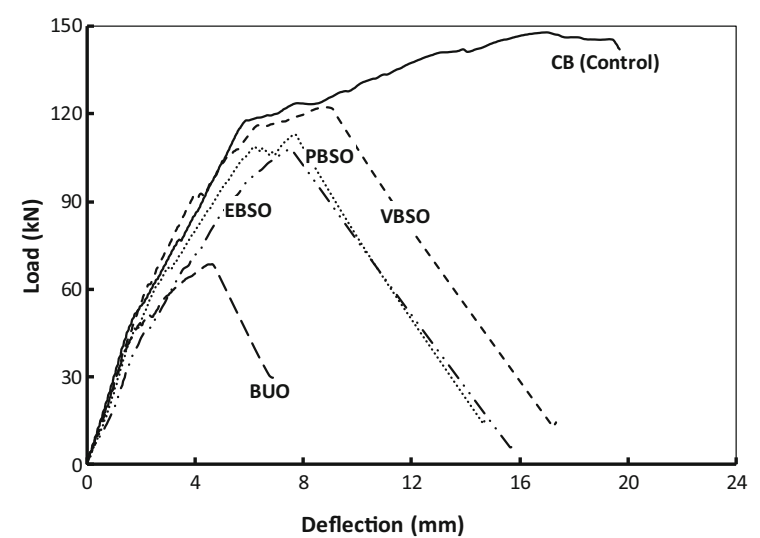

Fig. 4 Load-deflection comparison between strengthening performance of BFRC with epoxy, polyester and vinyl-ester resins

beams exhibited a ductile behaviour with a gradual increase in load before beam failure. Both the beams, $\mathrm{CB}$ achieved an ultimate load of $150 \mathrm{kN}$ at deflection

Table 2 Experimental results of shear strengthened RC beams with openings using BFRC plates

\begin{tabular}{lllll}
\hline $\begin{array}{l}\text { Beam } \\
\text { designation }\end{array}$ & $\begin{array}{l}\text { First crack load } \\
(\mathrm{kN})\end{array}$ & $\begin{array}{l}\text { Mid-span deflection at first crack load } \\
(\mathrm{mm})\end{array}$ & $\begin{array}{l}\text { Ultimate load } \\
(\mathrm{kN})\end{array}$ & $\begin{array}{l}\text { Mid-span deflection at ultimate load } \\
(\mathrm{mm})\end{array}$ \\
\hline CB & 50.5 & 1.85 & 150 & 16.3 \\
BUO & 45.5 & 1.7 & 70 & 6.1 \\
EBSO & 44 & 2.1 & 108 & 7.6 \\
PBSO & 45 & 1.7 & 113 & 7.7 \\
VBSO & 46 & 1.7 & 122 & 8.9 \\
\hline
\end{tabular}


of $16.3 \mathrm{~mm}$. Due to the presence of circular openings at the shear spans, a significant reduction of load in the range of $52-55 \%$ was identified in beams BUO compared to the control beams. The reduction of a cross-sectional area of the concrete beam greatly reduced the beam capacity similar to the previous findings [13]. After reaching the ultimate load, both the beams showed a sharp decrease upon failure which indicated a brittle behaviour. The RC beam with openings strengthened using BFREC plates (EBSO) showed a significant improvement in the beam structural capacity with the ultimate load up to $36 \%$ higher than the unstrengthened beam (BUO). The loaddeflection curve trend of EBSO was found similar to that of BUO, whereby a sudden drop was observed after reaching the maximum load. The beam EBSO was unable to fully restore the original beam capacity of the control beams. However, up to $73 \%$ of the control beam capacity was achieved using a BFREC strengthening, in comparison to the unstrengthen beam which only had $46.6 \%$ of the control beam capacity. Strengthening with BFREC plates showed some improvement over the unstrengthen beam, however the deflections was still much lower compared to the control beams. The maximum deflections of beams were found to be about $70 \%$ lesser than control beams.

It was found that all the strengthened beams with openings using BFRC with various types of resins achieved almost similar beam stiffness as the control beam at the early stage of loading (Table 2). However, the beam stiffness started to reduce after reaching the first crack at about 44-46 kN. From the loaddeflection curve, it can be seen that all the BFRC plates with various types of resins were unable to regain the original beam capacity of the control beam (CB). BFRC with vinyl-ester resin (VBSO) exhibited the highest ultimate load $122 \mathrm{kN}$ at $8.9 \mathrm{~mm}$ deflection, which was approximately $82 \%$ of the beam capacity of CB. After the ultimate load was attained, the beam showed a brittle failure rather than ductile behaviour observed in $\mathrm{CB}$. Meanwhile, the polyester based BFRC (PBSO) gave the second highest ultimate load $(113 \mathrm{kN})$ and deflection of $7.7 \mathrm{~mm}$. The PBSO managed to regain $76 \%$ of the control beam capacity. The BFRC based epoxy (EBSO) gave the lowest performance among all resins tested. The EBSO had an ultimate load of $108 \mathrm{kN}$ with a deflection of $7.6 \mathrm{~mm}$, which was within $73 \%$ of the control beam capacity. The difference between the BFRC based on the three polymer resins tested was less than $15 \%$. The ultimate load reduction after the beam failure showed similar pattern for all types of BFRCs tested. Due to the presence of openings in both the shear zones, the failure mode of all the bamboo fiber composites with various resins exhibited brittle failure, similar to the unstrengthened beam, BUO-2 after reaching the ultimate load. However, the load decreased with increase in deflection due to the strengthening effects around the openings. BFREC has a slightly higher flexural strength than the BFRVC and BFRPC, although the difference is not significant $(\mathrm{p}>0.05)$. However, the beam strengthened by BFRVC (VBSO) in shear zone has a slightly higher beam capacity than EBSO. This may be due to the ability of vinyl ester to endure a greater ultimate deflection than that of epoxy, hence resisting the beam failure in shear slightly better. Table 2 shows that the ultimate deflection of VBSO is $8.9 \mathrm{~mm}$, which is $14.6 \%$ greater than that of EBSO. Similarly, the deflection of PBSO is greater than that of EBSO, which explained the reason of the lowest beam capacity of EBSO.

\subsubsection{Failure modes and crack pattern}

The failure modes of the solid beam, $\mathrm{CB}$, unstrengthen beam, BUO and the shear strengthened beams with openings with BFREC plates, EBSO are shown in Fig. 4a,b and c, respectively. The control specimens without strengthening experienced a flexural failure with several vertical cracks. The cracks first appeared at mid-span and propagated to the beam neutral axis. All the vertical cracks were propagated vertically from the soffit of the beam as shown in Fig. 5a. The cracks were widened in width upon beam failure. The failure mode of the beam was in bending.

With the provision of circular opening at both shear spans, it can be seen that the diagonal cracks were first initiated at the bottom chord of the right circular opening of the unstrengthen beam, BUO as shown in Fig. 5b. The diagonal crack then extended diagonally towards the support. At the same time, vertical cracks were formed along the tension zone. With further increment of load, diagonal cracks were developed at the top and bottom chords of the openings towards the loading point and supports, respectively. Premature failure occurred abruptly at the concrete struts by forming $45^{\circ}$ principal diagonal cracks at the top and 

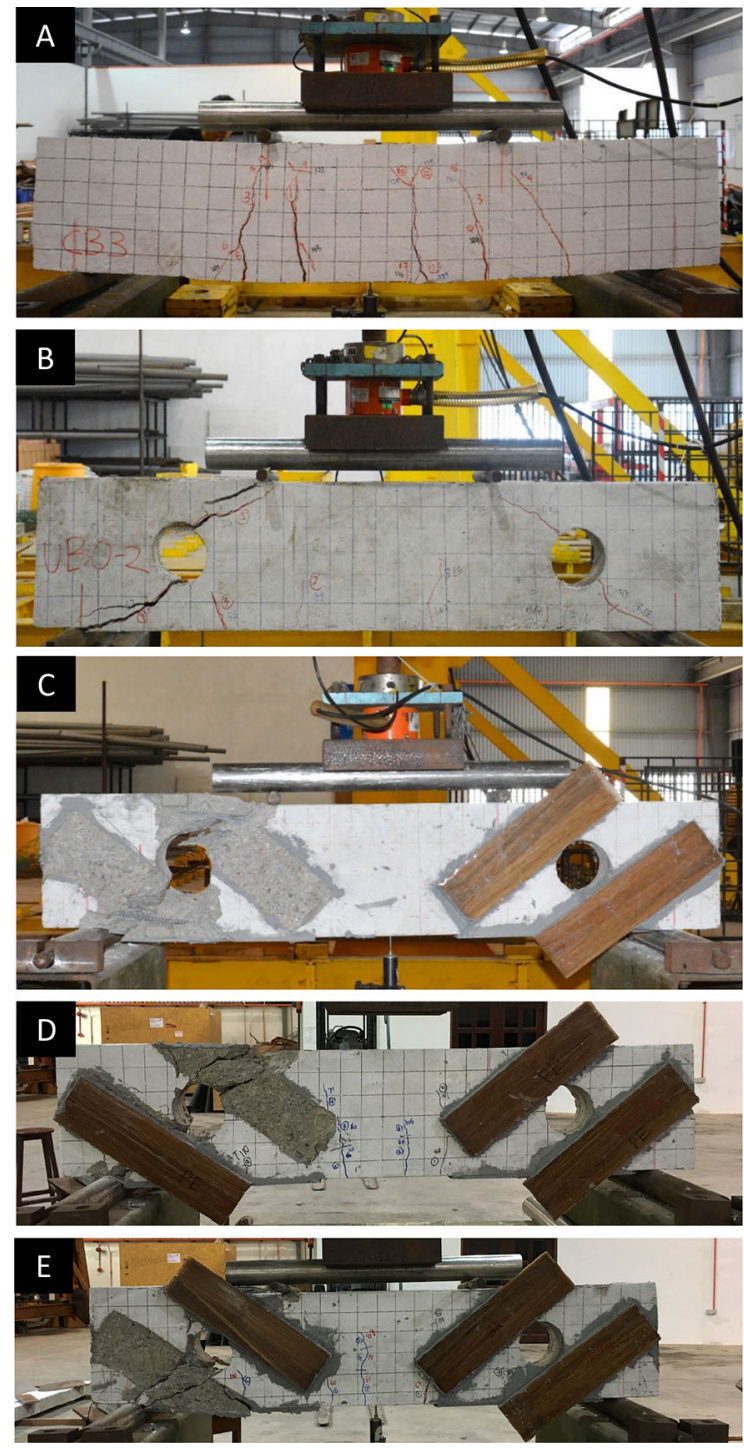

Fig. 5 Failure mode and crack pattern of various beam specimens. A CB, B BUO, C EBSO, D PBSO, E VBSO

bottom chords of the opening with respect to the beam longitudinal axis. The presence of openings in shear interrupted the original load path of the beam that led to stress concentration around the openings. This had caused the formation of diagonal cracks that separated the beam into two segments at the top and bottom chords, respectively.

Failure mode and crack patterns of the strengthened RC beams with openings using BFREC, EBSO is shown in Fig. 5c. Based on the observed crack pattern in beam BUO, the BFREC plates were bonded perpendicular to the predicted diagonal crack at the top and bottom chords of the openings, respectively. Fine vertical cracks were seen initiated in the middle span away from the strengthened area. With the continuous increment of load, a sudden failure in shear was observed with the formation of two independent diagonal cracks at the top and bottom chords of the left opening due to yielding of steel reinforcement. The failure pattern was found similar to that observed in the unstrengthen beam, BUO. The diagonal crack had caused debonding with peeling of concrete cover on the BFREC plate as shown in Fig. 6. The end of BFREC without concrete residue is not initially bonded with the beam, and it is not due to failure at the adhesive interface. Crushing of concrete occurred at the top chord of the opening was due to the yielding of steel reinforcement and the peeling of concrete with BFREC plate. There was neither premature debonding failure, fiber fracture nor pull out failure of BFREC plates which was traced up to beam failure. The failure was found to be brittle and catastrophic.

Figure 5d and e show the failure mode and crack pattern of RC beams with opening strengthened with BFRC-polyester and vinyl-ester, respectively. It was found that all the failure modes were similar to that of strengthened beam with BFRC-epoxy as shown in Fig. 5c. Vertical cracks were initiated in the middle span of the beam away from the strengthened regions in shear. With the continuous application of load, the vertical cracks then penetrated to the neutral axis of the beam. The beams eventually experienced a brittle and catastrophic failure in shear after reaching the maximum load. Both the BFRC-polyester and vinylester plates were debonded from the beam surface due to the diagonal crack propagation formed at the top chord above the opening strengthened using BFRCpolyester (Fig. 5d). Similarly, due to the formation of

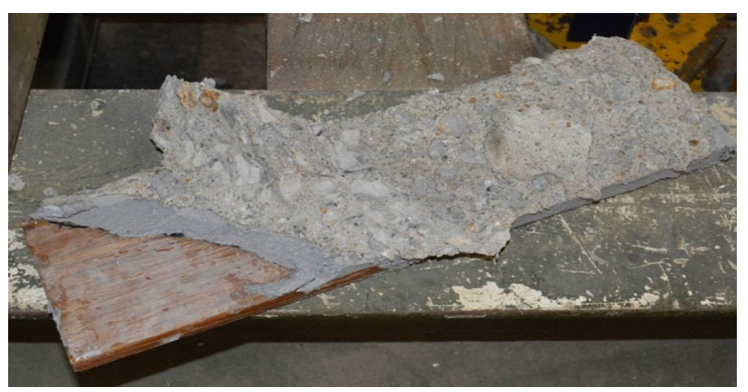

Fig. 6 Debonding with peeling of concrete cover on the BFREC plate 
diagonal cracks at the bottom chord of the opening towards the support, BFRC-vinyl-ester plate (Fig. 5e) were debonded from the concrete surface. The crack formation and yielding of steel reinforcement led to crushing of concrete cover at the compression zone as well as at the left support, in BFRC-polyester and BFRC-vinyl-ester plates, respectively.

\subsection{Structural behaviour of flexural strengthened $\mathrm{RC}$ beams with BFREC plates}

\subsubsection{Load-deflection behaviour}

Figure 7 shows the load-deflection behaviour of RC beams strengthened in flexure using BFREC plates. Summary of the experimental results is presented in Table 3. It was observed that the control beams, CB behave linearly elastic at the early stage of loading. After the first crack, the beams entered into plastic phase and attained an ultimate load of up to $124 \mathrm{kN}$ at a deflection of $7 \mathrm{~mm}$, before a sharp decrease in load was observed upon beam failure. This indicated a brittle beam failure. Meanwhile, the unstrengthened beams with removal of shear link in the tension zone, BUF exhibited a slight decrease in beam stiffness compared to the control beams. The beams BUF reached a maximum load of up to $115 \mathrm{kN}$ at a deflection of $8.5 \mathrm{~mm}$ before beam failure. Same trend of load-deflection curve was observed as compared to that of the control beams in which the beam failed immediately after reaching the ultimate load. Compared to the control beams, the weakened beams in flexure showed a reduction of load to about $3-10 \%$ and

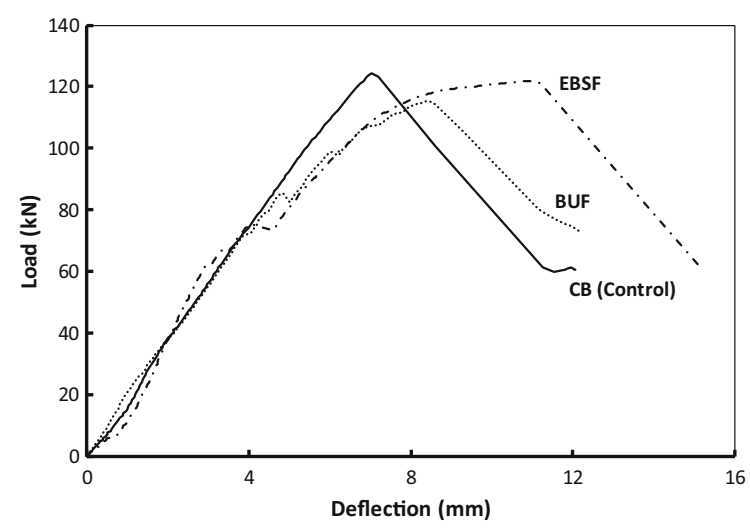

Fig. 7 Load-deflection behaviour comparison of RC beam strengthened in flexure using BFREC plates increment the beam deflection to about $13-20 \%$. It was found that strengthening of RC beams in flexure with BFREC plates (EBSF) improved the beam capacity up to $122 \mathrm{kN}$, which is about $98 \%$ of the control beam (CB) capacity $(124 \mathrm{kN})$. After the first crack, the load increased gradually with increases in deflection before beam failure. Upon failure, the load reduced in a gradual manner with an increase in deflection. This showed that the BFREC plates managed to mitigate and change the failure mode brittle failure to a more ductile behaviour.

\subsubsection{Failure mode and crack pattern}

Different types of failure modes were observed in the experimentation of $\mathrm{RC}$ beams strengthened in flexure by BFREC plates. The control beams CB failed in a mix mode of bending and shear failure. Major vertical cracks developed in the mid span firstly initiated at the lower face at the bottom side of the beam. These cracks eventually penetrated up to the neutral axis towards the compression zone. The flexural cracks also extended along the tension zone towards the supports which indicated a combination of vertical and diagonal cracks. The diagonal cracks propagated towards the loading points and failed abruptly with increase crack width upon beam failure. Both the control beams failed in similar manner as shown in Fig. 8a.

With the removal of shear link in the mid span, the unstrengthened beams, BUF exhibited higher number of vertical cracks in the mid span (Fig. 8b) compared to the control beams, CB. The flexural cracks eventually propagated vertically towards the neutral axis of the beam with the increase of load. At the same time, these flexural cracks formed along the tension zone of the beam near to the support. These cracks eventually penetrated from the supports towards the loading points forming diagonal cracks. The crack width of the diagonal cracks near to the support became significant upon beam failure. The beam failed in a combination of bending and shear failures.

Figure $8 \mathrm{c}$ shows the failure mode and crack pattern of the strengthened RC beams in flexure by BFREC plates. When load was first applied, only a few vertical cracks were seen in the tension zone of the beam compared to the control and unstrengthened beams. On further increment of load, the vertical cracks propagated towards the neutral axis of the beam. This 
Table 3 Experimental results of flexural strengthened RC beam BFREC plates

\begin{tabular}{lllll}
\hline $\begin{array}{l}\text { Beam } \\
\text { designation }\end{array}$ & $\begin{array}{l}\text { First crack load } \\
(\mathrm{kN})\end{array}$ & $\begin{array}{l}\text { Mid-span deflection at first crack load } \\
(\mathrm{mm})\end{array}$ & $\begin{array}{l}\text { Ultimate load } \\
(\mathrm{kN})\end{array}$ & $\begin{array}{l}\text { Mid-span deflection at ultimate load } \\
(\mathrm{mm})\end{array}$ \\
\hline CB & 38 & 2.0 & 124 & 7.0 \\
BUF & 72 & 3.9 & 115 & 8.5 \\
EBSF & 62 & 2.9 & 122 & 11.1 \\
\hline
\end{tabular}
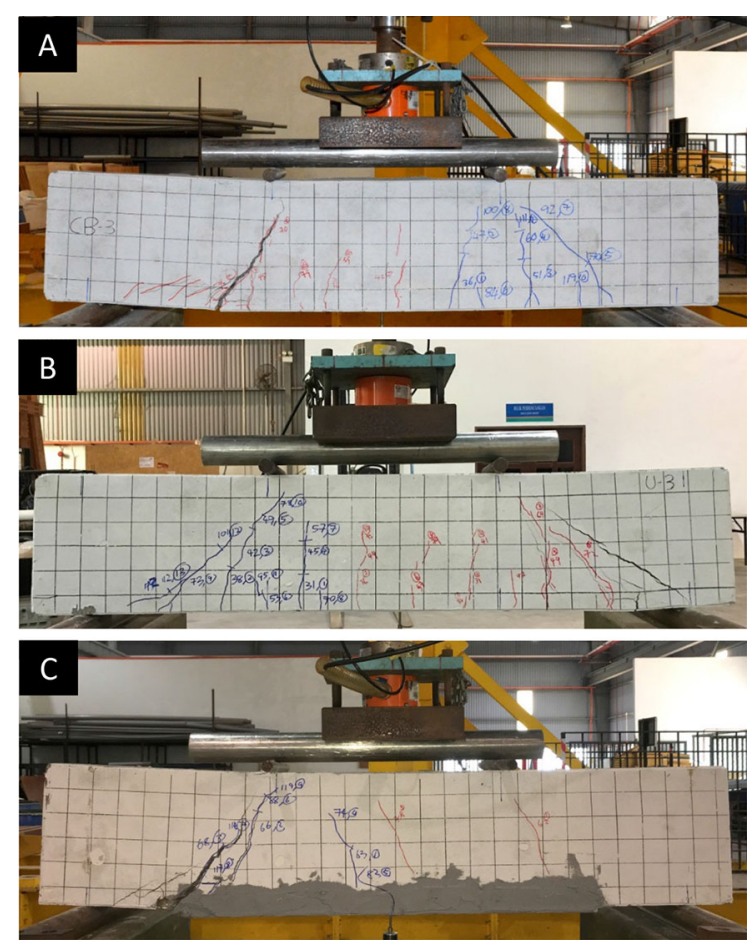

Fig. 8 Failure mode and crack pattern of various beam specimens. A CB, B BUF, C EBSF

showed that the presence of BFREC plates had diverted most of the vertical cracks away from the strengthened region. Eventually, cracks were initiated at the left edge of the BFREC plate and propagated diagonally towards the loading point. The width of the diagonal cracks was further widened with the increase of load. The beam failed in shear with widened shear cracks near to the edge of the BFREC plates. There was no debonding of the composite plate traced from the beginning of experimental testing up to beam failure.

\section{Conclusions}

In the study herein, the use of bamboo fiber reinforced composite (BFRC) as external strengthening material for shear strengthening of RC beams with openings as well as flexural strengthening of solid RC beams were studied. The following conclusions can be drawn based on the results obtained.

1 Epoxy based BFRC with $40 \%$ fiber content showed the highest tensile and flexural strength, thus it was used for the concrete beam strengthening test in this work. It was found that at higher bamboo fiber content, the mechanical properties of BFRC plates were independent of the type of polymer used

2 Shear strengthening of RC beams with openings using BFREC plates showed significant improvement in regaining the beam structural capacity to approximately $32-36 \%$ higher than the unstrengthened beams. Comparing to the control beams, the strengthened beams with BFREC plates were unable to fully restore the original beam capacity but managed to regain the beam capacity of the control beams to about $68-73 \%$. Strengthening with BFREC plates could reduce the beam deflection and number of cracks.

3 Strengthening of RC beams in flexure with BFREC plates managed to regain the beam original capacity up to $98 \%$ of the control beam. This showed that the BFREC plates managed to mitigate and change the failure mode from brittle to a more ductile behaviour.

4 Shear strengthening of RC beams with openings using bamboo fiber composite plates with epoxy, polyester and vinyl-ester resins of $40 \%$ fiber volume fraction managed to regain the beam original capacity to about $70-82 \%$. Although vinyl-ester and polyester composites showed 
slightly higher performance than epoxy strengthened BFRC plates, the difference between the ultimate load achieved was very small which was in the range of $12-15 \%$.

5 All BFRC plates could divert the cracks formation away from the strengthened region as well as mitigate the appearance of cracks in both flexural and shear spans.

Acknowledgements We acknowledge the research funding from Universiti Malaysia Pahang (RDU180349 \& RDU1803105) and the Ministry of Education, Malaysia (RAGS/1/2015/TK01/UMP/02/1). We acknowledge the collaborative research funding from University of Greenwich.

Open Access This article is licensed under a Creative Commons Attribution 4.0 International License, which permits use, sharing, adaptation, distribution and reproduction in any medium or format, as long as you give appropriate credit to the original author(s) and the source, provide a link to the Creative Commons licence, and indicate if changes were made. The images or other third party material in this article are included in the article's Creative Commons licence, unless indicated otherwise in a credit line to the material. If material is not included in the article's Creative Commons licence and your intended use is not permitted by statutory regulation or exceeds the permitted use, you will need to obtain permission directly from the copyright holder. To view a copy of this licence, visit http://creativecommons.org/licenses/by/4.0/.

\section{References}

1. Abdalla H (2003) Design against cracking at openings in reinforced concrete beams strengthened with composite sheets. Compos Struct 60(2):197-204. https://doi.org/10. 1016/S0263-8223(02)00305-7

2. Abduljalil BS (2014) Shear resistance of reinforced concrete deep beams with opening strengthened by CFRP strips. J Eng Dev 18(1):14-32

3. Alam A, Hassan A, Muda ZC (2016) Development of kenaf fibre reinforced polymer laminate for shear strengthening of reinforced concrete beam. Mater Struct 49(3):795-811. https://doi.org/10.1617/s11527-015-0539-0

4. Alam A, Nouri K (2015) Flexural strengthening of reinforced concrete beam using jute rope composite plate. The 3rd National Graduate Conference (NatGrad2015). Putrajaya, Malaysia, pp 8-9

5. Alam MA, Al Riyami K (2018) Shear strengthening of reinforced concrete beam using natural fibre reinforced polymer laminates. Constr Build Mater 162:683-696. https://doi.org/10.1016/j.conbuildmat.2017.12.011

6. Allam SM (2005) Strengthening of RC beams with large openings in the shear zone. Alex Eng J 44(1):59-78

7. Aslam MP, Shafigh MJ, Shah S (2015) Strengthening of RC beams using prestressed fiber reinforced polymers-A review. Constr Build Mater 82:235-256. https://doi.org/10. 1016/j.conbuildmat.2015.02.051

8. Bharath GR, Jagannatha Reddy HN (2015) Strengthening of Post-tensioned beams by externally bonded and anchored natural sisal fiber reinforced polymer composites. Int Res J Eng Technol (IRJET) 2(06):127-142

9. Bourmaud A, Le Duigou A, Gourier C, Baley C (2016) Influence of processing temperature on mechanical performance of unidirectional polyamide 11-flax fibre composites. Ind Crops Prod 84:151-165. https://doi.org/10.1016/j. indcrop.2016.02.007

10. Chen H, Cheng H, Wang G, Qiang Shi S (2015) Tensile properties of bamboo in different sizes. J Wood Sci 61(6):552-561. https://doi.org/10.1007/s10086-015-1511-x

11. Chen H, Zhang W, Wang X, Wang H, Wu Y, Zhong T, Fei B (2018) Effect of alkali treatment on wettability and thermal stability of individual bamboo fibers. J Wood Sci 64(4):398-405. https://doi.org/10.1007/s10086-018-1713-0

12. Chin SC, Shafiq N, Nuruddin MF (2012) Strengthening of $\mathrm{RC}$ beams with large openings in shear by CFRP laminates: Experiment and 2D nonlinear finite element analysis. Res J Appl Sci Eng Tech 4(9):1172-1180

13. Chin SC, Shafiq N, Nuruddin MF (2016) Behaviour of RC beams with CFRP-strengthened openings. Struct Concrete 17(1):32-43. https://doi.org/10.1002/suco.201400111

14. Chin SC, Tee KF, Tong FS, Ong HR, Gimbun J (2020) Thermal and mechanical properties of bamboo fiber reinforced composites. Mater Today Com 23:100876

15. Esmaeeli E, Danesh F, Tee KF, Eshghi S (2017) A combination of GFRP sheets and steel cage for seismic strengthening of shear-deficient corner RC beam-column joints. Compos Struct 159:206-219

16. Gopinath A, Senthil Kumar M, Elayaperumal A (2014) Experimental investigations on mechanical properties of jute fiber reinforced composites with polyester and epoxy resin matrices. Procedia Eng 97:2052-2063. https://doi.org/ 10.1016/j.proeng.2014.12.448

17. Hafizah NA, Bhutta MAR, Jamaludin MY, Warid MH, Ismail M, Rahman MS, Yunus I, Azman M (2014) Kenaf fiber reinforced polymer composites for strengthening RC beams. J Adv Concr Technol 12:167-177. https://doi.org/ 10.3151/jact.12.167

18. Hojo T, Xu Z, Yang Y (2014) Tensile properties of bamboo, jute and kenaf mat-reinforced composite. Energy Procedia 56:72-79. https://doi.org/10.1016/j.egypro.2014.07.133

19. Huang J, Young W (2019) The mechanical, hygral, and interfacial strength of continuous bamboo fiber reinforced epoxy composites. Compos Part B-Eng 166:272-283. https://doi.org/10.1016/j.compositesb.2018.12.013

20. Khan AQ, Hussain Q, Rattanapitikon W, Pimanmas A (2016) Flexural strengthening of RC beams with sisal fiber composites and sisal fiber rods. Mater Sci Forum 860:144-147. https://doi.org/10.4028/www.scientific.net/ MSF.860.144

21. Liu Y, Hu H (2008) X-ray diffraction study of bamboo fibers treated with $\mathrm{NaOH}$. Fiber Polym 9(6):735-739. https://doi. org/10.1007/s12221-008-0115-0

22. Nadjai A, Goodfellow N, Tee KF, Ali F, Choi SK (2010) Analysis of composite floor cellular steel beams in fire. J Struct Fire Eng 1(3):161-175 
23. Okubo K, Fujii T, Yamamoto Y (2004) Development of bamboo-based polymer composites and their mechanical properties. Compos Part A-Appl S 35(3):377-383. https:// doi.org/10.1016/j.compositesa.2003.09.017

24. Osorio LE, Trujillo AW, Vuure V, Verpoest I (2011) Morphological aspects and mechanical properties of single bamboo fibers and flexural characterization of bamboo / epoxy composites. J Reinf Plast Comp 30(5):396-408. https://doi.org/10.1177/0731684410397683

25. Pimanmas A (2010) Strengthening R/C beams with opening by externally installed frp rods: behavior and analysis. Compos Struct 92(8):1957-1976. https://doi.org/10.1016/j. compstruct.2009.11.031

26. Ramesh M, Palanikumar K, Hemachandra Reddy K (2013) Mechanical property evaluation of sisal-jute-glass fiber reinforced polyester composites. Compos Part B-Eng 48:1-9. https://doi.org/10.1016/j.compositesb.2012.12.004

27. Rao KMM, Rao KM (2007) Extraction and tensile properties of natural fibers: Vakka, date and bamboo. Compos Struct 77(3):288-295. https://doi.org/10.1016/j.compstruct. 2005.07.023

28. Rassmann S, Paskaramoorthy R, Reid RG (2011) Effect of resin system on the mechanical properties and water absorption of kenaf fibre reinforced laminates. Mater Des 32(3):1399-1406. https://doi.org/10.1016/j.matdes.2010. 09.006

29. Salman SD, Sharba MJ, Leman Z, Sultan MTH, Ishak MR, Cardona F (2015) Physical, mechanical, and morphological properties of woven kenaf/polymer composites produced using a vacuum infusion technique. Int $\mathbf{J}$ of Polym Sci 2015:894565. https://doi.org/10.1155/2015/894565

30. Samad AAA, Ali N, Mohamad N, Jayaprakash J, Tee KF, Mendis P (2017) Shear strengthening and shear repair of 2 -span continuous RC beams with CFRP strips. Journal of Composites for Construction, ASCE 21(3):04016099

31. Sen T, Jagannatha Reddy HN (2014a) Flexural strengthening of RC beams using natural sisal and artificial carbon and glass fabric reinforced composite system. Sustain Cities Soc 10:195-206. https://doi.org/10.1016/j.scs.2013.09.003

32. Sen T, Jagannatha Reddy HN (2014b) Strengthening of RC beams in flexure using natural jute fibre textile reinforced composite system and its comparative study with CFRP and GFRP strengthening systems. Int J Sustain Built Environ 2(1):41-55. https://doi.org/10.1016/j.ijsbe.2013.11.001

33. Spinella N (2019) Modeling of shear behavior of reinforced concrete beams strengthened with FRP. Compos Struct 215:351-364. https://doi.org/10.1016/j.compstruct.2019. 02.073

34. Sundarraja MC, Rajamohan S (2009) Strengthening of RC beams in shear using GFRP inclined strips-An experimental study. Constr Build Mater 23(2):856-864. https://doi.org/ 10.1016/j.conbuildmat.2008.04.008

35. Tong FS, Chin SC, Mustafa MT, Ong HR, Khan MMR, Gimbun J, Doh SI 2018 Influence of alkali treatment on physico-chemical properties of Malaysian bamboo fiber: A preliminary study. Malaysian J Anal Sci, 22(1): 143-150 https://doi.org/10.17576/mjas-2018-2201-18

36. Yang M, Wang F, Zhou S, Lu Z, Ran S, Li L, Shao J (2019) Thermal and mechanical performance of unidirectional composites from bamboo fibers with varying volume fractions. Polym Compos 40(10):3929-3937. https://doi.org/10. $1002 / p c .25253$

37. Zhang K, Wang F, Liang W, Wang Z, Duan Z, Yang B (2018) Thermal and mechanical properties of bamboo fiber reinforced epoxy composites. Polym-Basel 10(6):608. https://doi.org/10.3390/polym10060608

38. Zhang X, Wang F, Keer LM (2015) Influence of surface modification on the microstructure and thermo-mechanical properties of bamboo fibers. Materials 8(10):6597-6608. https://doi.org/10.3390/ma8105327

Publisher's Note Springer Nature remains neutral with regard to jurisdictional claims in published maps and institutional affiliations. 